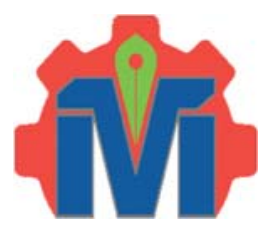

JMI Vol. 38 No. 1 Juni 2016

METAL INDONESIA

Journal homepage:

http://www.jurnalmetal.or.id/index.php/jmi

p-issn: $0126-3463$

e-issn : 2548-673X

\title{
PENGARUH KROM TERHADAP SIFAT MEKANIK DAN STRUKTUR MIKRO PADA BESI COR NODULAR 400
}

\section{EFFECT OF CROM ON MECHANICAL PROPERTIES AND METALOGRAPHY OF FCD 400}

\author{
Martin Doloksaribu dan Eva Afrilinda \\ Balai Besar Logam dan Mesin, Kementerian Perindustrian \\ Jalan Sangkuriang 12 Bandung, Jawa Barat 40135 \\ Email: martin-d@kemeperin.go.id, eva.afrilinda@gmail.com)
}

\begin{abstract}
Abstrak
Besi Tuang Nodular 400 (FCD 400) dengan standar komposisi 3,5 3,9\%C, 2,5 2,9\% $\mathrm{Si}, 0,3 \sim 0,5 \% \mathrm{Mn}$, maks $0,03 \% \mathrm{P}$, maks $0,02 \% \mathrm{~S}$ dan $\min 0,03 \% \mathrm{Mg}$. Besi Cor Nodular memiliki perpaduan sifat kekuatan dan keuletan. Pada aplikasi slider tebal diperlukan kepastian sifat ketahanan aus. Ketahanan aus ditingkatkan dengan meningkatkan kekerasan dan kekuatan tarik. Krom $(\mathrm{Cr})$ merupakan unsur yang dapat meningkatkan kekerasan karena dapat berperan sebagai promotor perlit dan karbida. Pada pembuatan Besi Cor Nodular 400 ditambahkan Cr pada kisaran 0,03 0,1\%. Uji tarik dan uji keras pada $0,033 \% \mathrm{Cr}$ sebesar 431,68 N/mm dan $157 \mathrm{HB}$. Pada 0,074\%Cr sebesar 599,28 N/mm² dan $187 \mathrm{HB}$. Struktur mikro menunjukkan peningkatan kandungan perlit yang signifikan.
\end{abstract}

Kata Kunci : besi cor nodular 400, krom, kekuatan tarik, kekerasan, kekerasan, perlit

\begin{abstract}
Nodular Cast Iron 400 (FCD 400) has a standard composition C 3.5 3.9\%, Si 2.5 2.9\%, Mn 0.3 0.5\%, $P$ max of $0.03 \%, S$ max of $0.02 \%$ and $0.03 \%, M g$ min. Nodular Cast Iron has good combination of strength and ductility. Heavy section casting of slider application requires good wear resistance which influenced by tensile strength and hardness. Wear resistance can be developed by increasing tensile strength and hardness. Chromium can improve strength and hardness as pearlite and carbides promote. Chrome was added on FCD 400 by $0.03 \sim 0.1 \%$. Tensile strength and hardness test at $0.033 \% \mathrm{Cr}$ were $431.68 \mathrm{~N} / \mathrm{mm}^{2}$ and $157 \mathrm{HB}$; at $0.074 \% \mathrm{Cr}$ were $599.28 \mathrm{~N} / \mathrm{mm}^{2}$ and $187 \mathrm{HB}$. The microstructure shows that hard pearlite structure was not significantly increased.
\end{abstract}

Keywords : ductile cast iron 400, chrom, tensile strength, hardness, pearlite

\section{PENDAHULUAN}

Besi Tuang Nodular (BTN) merupakan material yang serba guna (Melnikov and Filipenka 2011). Grafit spheroidal pada BTN menghasilkan kisaran perpaduan sifat mekanik yang luas. Perpaduan sifat yang dimiliki seperti keuletan dan ketangguhan, ketahanan korosi dan ketahanan panas.

Produk yang terbuat dari Besi Tuang Kelabu (BTK) atau steel pada aplikasi tertentu dapat digantikan oleh BTN. BTK memiliki kekuatan tarik maksimal berkisar 280 343 $\mathrm{MPa}$ (Pluphrach 2010) sedangkan BTN memiliki kisaran UTS 350 800 namun memiliki elongasi $2 \sim 22 \%$. Dengan menggunakan BTN, produk/komponen memiliki perpaduan tensile strength dengan ductility. Perpaduan sifat tersebut memberikan ketahanan pakai yang lebih baik dibandingkan BTK.

Perpaduan kekuatan tarik dan kekerasan BTN disebabkan oleh grafit berbentuk nodular dan struktur mikro yang terbentuk. Sifat BTN dalam skala tertentu dapat dicapai dengan mengontrol struktur mikro yang terbentuk (Omran, AbdelJaber, and Ali 2014). Struktur matriks dalam struktur mikro pada BTN dapat berbentuk ferritik, perlitik, ferritik-perlitik, martensitik, austenitik atau bainitik. Struktur matriks BTN 
pada kondisi as-cast adalah ferritik, perlitik atau ferritik-perlitik.

Pengaturan struktur mikro dapat dilakukan dengan memberikan perlakuan panas pada produk atau dengan menggunakan unsur paduan tertentu (Madtha and Babu 2013). Pengaturan struktur mikro pada as-cast dengan perlakuan panas memerlukan tambahan waktu dan biaya pengerjaan. Rekayasa struktur mikro dengan penggunaan unsur paduan tertentu tidak memerlukan tambahan waktu pengerjaan sehingga biaya yang dibutuhkan relatif lebih murah. Oleh karena itu metode pengaturan struktur mikro dengan penggunaan unsur paduan lebih praktis dan murah.

Pada beberapa aplikasi tertentu produk diinginkan memiliki sifat lebih baik daripada standar sifat material. Salah satunya seperti pada komponen slider. Komponen tersebut dibuat dari BTN 400 dengan peningkatan pada beberapa sifat mekanik supaya memenuhi kebutuhan. Sifat yang diinginkan adalah perpaduan antara kekuatan dan ketahanan aus. Ketahanan aus didapat dari perpaduan keuletan dan kekeraasan.

BTN 400 merupakan standar besi cor Jepang dengan komposisi karbon 3,5 3,9; silikon 2,5 2,9; mangan 0,3 0,5; fosfor maksimal 0,05; sulfur maksimal 0,02 dan magnesium minimal $0,03 \%$. Kekuatan tarik (tensile strength) sebesar $400 \mathrm{~N} / \mathrm{mm}^{2}$, elongasi $15 \sim 18 \%$ dan kekerasan (hardness) 130 180 HB.

Penambahan unsur krom (Cr) pada BTN memberikan pengaruh yang berbeda-beda pada spesifikasi BTN yang berbeda. Pada heavy section ductile cast iron, penambahan $\mathrm{Cr}$ sebesar 0,26 dan $0,49 \%$ akan meningkatkan kekuatan (strength) dan kekerasan secara signifikan (Cho et al. 2007). Kekuatan tarik meningkat dari sekitar 440 ke $590 \mathrm{MPa}$ dan kekerasan meningkat dari 170 ke 220 HB. Namun penambahan unsur $\mathrm{Cr}$ menurunkan elongasi dari $13 \mathrm{ke} 7 \%$. Struktur mikro menunjukkan struktur bull's eye di dalam matriks perlit.

Hasil penelitian lain menunjukkan pengaruh $\mathrm{Cr}$ sampai dengan $1,00 \%$ dan $\mathrm{Cu}$ sampai dengan $1,50 \%$ pada BTN dengan kandungan karbida pada struktur mikro (Gumienny 2010). Peningkatan kandungan $\mathrm{Cr}$ dari 0,25 ke 0,50\% mengurangi area ferit namun meningkatkan area karbida sehingga dapat meningkatkan kekerasan dari 303 menjadi 360 HB. Penambangan $\mathrm{Cr}$ $1,00 \%$ memberikan peningkatan kekerasan.
Pengaruh penambahan unsur paduan dipengaruhi oleh metode peleburan BTN (Válek, Šimon, and Stř́lková 2012). Metode peleburan BTN terdiri atas beberapa tahap antara lain tahap inokulasi dan spheroidisasi. Proses spheroidisasi yang intens dan lambat akan menyebabkan penurunan kandungan karbon (C) dan kandungan residu magnesium (Mg) (Bockus and Dobrovolskis 2005). Kandungan Mg perlu dijaga karena $\mathrm{Mg}$ berfungsi sebagai pembentuk grafit nodular.

Pada umumnya matriks yang terbentuk pada BTN 400 adalah ferrit. Si berfungsi sebagai promotor ferrit dan Mn berfungsi sebagai unsur yang meningkatkan kekuatan dan kekerasan matriks ferit sekaligus sebagai penstabil perlit yang di dalam besi cor nodular 400 (Gonzaga et al. 2009).

Pada beberapa kasus diperlukan material yang memiliki sifat yang lebih baik dibandingkan sifat standar dengan tetap memperhitungkan biaya produksi. Sifat BTN dapat ditingkatkan dengan penambahan unsur paduan. Pengaruh $\mathrm{Cr}$ terhadap sifat BTN dipengaruhi oleh beberap faktor antara lain jumlah penambahan $\mathrm{Cr}$ serta parameter peleburan. Parameter peleburan mempengaruhi kandungan unsur lain sehingga mempengaruhi efek dari penggunaan $\mathrm{Cr}$. Temperatur tinggi dan waktu tahan yang lama di tungku akan menurunkan kandungan unsur $\mathrm{C}$ namun meningkatkan Si. Spheroidisasi yang intens dan lambat mempengaruhi komposisi cairan dan kandungan residu $\mathrm{Mg}$ dalam besi nodular. Tujuan dari penelitian ini adalah untuk mengetahui pengaruh penambahan unsur paduan $\mathrm{Cr}$ dalam jumlah relatif sedikit terhadap kekuatan tarik dan kekerasan BTN 400.

\section{METODE}

Peleburan BTN menggunakan tungku induksi frekuensi rendah Inductoterm. Proses peleburan diawali dengan penyiapan material umpan (charging material). Material umpan yang digunakan adalah steel scarp $(0,02 \% \mathrm{C})$. Paduan yang digunakan adalah carburizer $(75 \% \mathrm{C})$, cover agent, $\mathrm{FeSiMg}, \mathrm{FeSi}$, inokulan dan $\mathrm{Cr}$. Charging material dimasukkan ke dalam tungku. Pemaduan dilakukan pada temperatur $\pm 1500^{\circ} \mathrm{C}$. Komposisi kimia diperiksa untuk menyesuaikan kandungan $\mathrm{C}$, Si dan $\mathrm{Mn}$ sesuai standar BTN 400 dan kandungan $\mathrm{Cr}$ sesuai target. Pengecekan komposisi kimia dilakukan pada chill test dengan spektrometer ARUN MetalScan PoySpek series. 
Pengecoran dilakukan dua kali dengan target kandungan $\mathrm{Cr}$ pada dua kisaran yaitu $\mathrm{Cr}<0,05 \%$ dan $0,05<\mathrm{Cr}<0,1 \%$.

Setelah komposisi kimia cairan logam tercapai maka dilakukan tapping. Cairan logam dituang ke pouring ladle. Bahan inokulasi diberikan pada saat tapping.

Spheroidisasi dilakukan di pouring ladle. Spheroidizer FeSiMg diletakkan di dasar ladel sehingga spheroidisasi terjadi sesaat setelah cairan logam menyentuh dasar ladel. Ilustrasi penempatan spheroidizer dapat dilihat pada Gambar 1. Cover agent diletakkan di atas spheroidizer agar spheroidizer tidak langsung habis terlarut ke cairan logam.

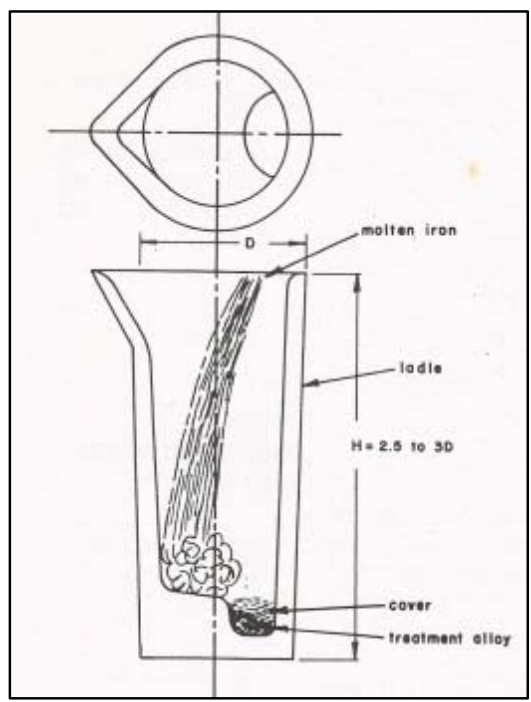

Gambar 1. Ilustrasi penempatan paduan spheroidizer (sumber: American Foundrymen's Society, Inc. 1986)

Cairan logam pada pouring ladle dituang ke cetakan blok Y. Cetakan dibuat dari pasir dengan resin alpha. Pada saat penuangan cairan ke cetakan, bahan inokulasi ditabur ke aliran cairan logam.

Pengujian mekanik dilakukan pada sampel. Uji tarik dilakukan sesuai standar JIS Z2201/1999. Pengujian dilakukan dengan alat uji tarik Universal Testing Machine Hung Ta dan diuji sesuai SNI. Uji keras dilakukan dari potongan sampel uji tarik. Uji keras menggunakan mesin AFRI Hardness Tester Serial No.4680 ROCKWELL B (HRB) indentor bola baja dengan beban $980 \mathrm{~N}$ dan penahanan beban selama 2 detik. Hasil uji keras didapat dalam satuan HRB kemudian dikonversi ke HB.
Pengamatan struktur mikro dilakukan dengan Mikroskop Nikkon Metaphot. Preparasi sampel menggunakan etsa nital $\left(\mathrm{FeCl}_{3}\right) 5 \%$. Pengamatan dilakukan pada perbesaran 50x, 100x, 200x dan 400x.

Kegiatan penelitian dilakukan di Balai Besar Logam dan Mesin Kementerian Perindustrian pada tahun 2015.

\section{HASIL \& PEMBAHASAN}

Hasil pengujian komposisi kimia dari dua kali pengecoran yang dilakukan ditunjukkan pada Tabel 1 dan Tabel 2.

Tabel 1. Hasil komposisi kimia cor kesatu

\begin{tabular}{|c|c|c|}
\hline Unsur & Standar BTN 400 & Hasil Cor \\
\hline $\mathrm{C}$ & $3.5 \sim 3.9$ & 3.580 \\
\hline $\mathrm{Si}$ & $2.5 \sim 2.9$ & 2.600 \\
\hline $\mathrm{Mn}$ & $0.3 \sim 0.5$ & 0.654 \\
\hline $\mathrm{Cr}$ & $<0.050$ & 0.033 \\
\hline $\mathrm{P}$ & $<0.05$ & 0.016 \\
\hline $\mathrm{S}$ & $<0.02$ & 0.032 \\
\hline $\mathrm{Mg}$ & $>0.03$ & 0.061 \\
\hline
\end{tabular}

Tabel 2. Hasil komposisi kimia cor kedua

\begin{tabular}{|c|c|c|}
\hline Unsur & Standar BTN 400 & Hasil Cor \\
\hline $\mathrm{C}$ & $3.5 \sim 3.9$ & 3.380 \\
\hline $\mathrm{Si}$ & $2.5 \sim 2.9$ & 2.800 \\
\hline $\mathrm{Mn}$ & $0.3 \sim 0.5$ & 0.544 \\
\hline $\mathrm{Cr}$ & $0.050 \sim 0.1$ & 0.074 \\
\hline $\mathrm{P}$ & $<0.05$ & 0.033 \\
\hline $\mathrm{S}$ & $<0.02$ & 0.022 \\
\hline $\mathrm{Mg}$ & $>0.03$ & 0.080 \\
\hline
\end{tabular}

Pada pengecoran pertama kandungan $\mathrm{Cr}$ sebesar $0,033 \%$ dan pada pengecoran kedua sebesar $0,074 \%$. 
Hasil uji tarik dapat dilihat pada Tabel 3.

Tabel 3. Hasil uji tarik

\begin{tabular}{|c|l|c|c|c|}
\hline No & Parameter Uji & Cor I & Cor II & $\begin{array}{c}\text { Standar } \\
\text { BTN 400 }\end{array}$ \\
\hline 1 & $\begin{array}{l}\text { Kekuatan tarik } \\
\left(\mathrm{N} / \mathrm{mm}^{2}\right)\end{array}$ & 431.68 & 599.28 & $\geq 400$ \\
\hline 2 & Elongasi (\%) & 16.04 & 13.13 & $15 \sim 18$ \\
\hline
\end{tabular}

Kekuatan tarik meningkat dari cor pertama terhadap cor kedua $(0,033 \%$ ke $0,074 \% \mathrm{Cr})$ sebesar 167,60 N/mm² (38,83\%). Pada kisaran tersebut matriks yang terbentuk ferritik/perlitik (Tabel 4). Pada cor kedua, kelebihan unsur S dan $\mathrm{Mn}$ dapat dikurangi. Kandungan sisa unsur $\mathrm{Mg}$ pada cor kedua lebih besar daripada cor pertama. Peningkatan kandungan unsur $\mathrm{Cr}$ bermanfaat terhadap kekuatan tarik (Soitiski and Derda 2008). Soitiski dan Derda meneliti pada kisaran $0,02 \sim 0,12 \% \mathrm{Cr}$. Namun peningkatan unsur $\mathrm{Cr}$ berdampak buruk terhadap nilai elongasi.

Tabel 4. Sifat mekanik FCD 400 pada as-cast dan annealed ferritic, ferritic/pearlitic, as-cast pearlitic dan normalized pearlitic

\begin{tabular}{|lc|c|c|c|c|}
\hline & & $\begin{array}{c}\text { As-cast and } \\
\text { annealed ferritic }\end{array}$ & Ferritic/pearlitic & $\begin{array}{c}\text { As-cast } \\
\text { pearlitic }\end{array}$ & $\begin{array}{c}\text { Normalised } \\
\text { pearlitic }\end{array}$ \\
\hline $\begin{array}{l}\text { Tensile } \\
\text { sterngth }\end{array}$ & $\mathrm{N} / \mathrm{mm}^{2}$ & $370 \sim 500$ & $500 \sim 600$ & $650 \sim 750$ & $750 \sim 1000$ \\
\hline $\begin{array}{l}0.1 \text { proof } \\
\text { strength }\end{array} \quad \mathrm{N} / \mathrm{mm}^{2}$ & $221 \sim 323$ & $323 \sim 346$ & $360 \sim 410$ & $410 \sim 550$ \\
\hline Elongation & $\%$ & $25 \sim 12$ & $7 \sim 3$ & $5 \sim 1$ & $7 \sim 2$ \\
\hline $\begin{array}{l}\text { Modulus } \\
\text { of elasticity }\end{array}$ & $\mathrm{GN} / \mathrm{m}^{2}$ & $168 \sim 170$ & $169 \sim 174$ & $175 \sim 177$ & $172 \sim 173$ \\
\hline $\begin{array}{l}\text { Harndness } \\
\text { No. }\end{array}$ & $\mathrm{HB}$ & $116 \sim 170$ & $172 \sim 247$ & $239 \sim 255$ & $255 \sim 300$ \\
\hline $\begin{array}{l}\text { Harndness } \\
\text { No. } \\
\text { (Konversi) }\end{array}$ & $\mathrm{HRB} / \mathrm{HRC}$ & $67.50 \sim 86.50 \mathrm{HRB}$ & $87 \mathrm{HRB} \sim 25 \mathrm{HRC}$ & $24 \sim 26 \mathrm{HRC}$ & $26 \sim 32 \mathrm{HRC}$ \\
\hline $\begin{array}{l}\text { Unnothche } \\
\text { d fatigue } \\
\text { limit }\end{array}$ & $\mathrm{N} / \mathrm{mm}^{2}$ & $186 \sim 224$ & $224 \sim 248$ & $360 \sim 300$ & $300 \sim 330$ \\
\hline $\begin{array}{l}\text { Notched } \\
\text { fatigue limit }\end{array}$ & $\mathrm{N} / \mathrm{mm}^{2}$ & $117 \sim 134$ & $134 \sim 149$ & $156 \sim 180$ & $180 \sim 200$ \\
\hline
\end{tabular}

Nilai elongasi mengalami penurunan dari cor pertama ke cor kedua sebesar 2,91\%elongasi. Elongasi cor kedua di bawah batas minimum standar.

Unsur $\mathrm{Mg}$ sebagai spheroidizer menyebabkan pembulatan inti. Kandungan $\mathrm{Mg}$ yang dimasukkan ke dalam cairan logam tidak seluruhnya bereaksi dalam pembentukan inti nodul. Peningkatan residu $\mathrm{Mg}$ meningkatkan kandungan perlit (Bockus and Zaldarys 2011). Perlit memiliki sifat lebih keras dibandingkan ferrit.
Kekurangan unsur $\mathrm{C}$, kelebihan unsur P-S dan peningkatan unsur $\mathrm{Cr}$ dapat menjadi faktor penghambat peningkatan efek pembulatan. Unsur P menyebabkan terbentuk fasa yang brittle. Unsur S reaktif terhadap Mg.

Hasil uji keras sebagai berikut (Tabel 5):

Tabel 5. Hasil uji keras

\begin{tabular}{|l|c|c|c|}
\hline $\begin{array}{c}\text { Parameter } \\
\text { Uji }\end{array}$ & Cor I & Cor II & $\begin{array}{c}\text { Standar BTN } \\
400\end{array}$ \\
\hline $\begin{array}{l}\text { Kekerasan } \\
(\mathrm{HB})\end{array}$ & 157.00 & 187.00 & $130-210$ \\
\hline
\end{tabular}

Penambahan kandungan unsur $\mathrm{Cr}$ dapat meningkatkan kekerasan (Jiang et al. 2016). Unsur $\mathrm{Cr}$ berfungsi sebagai promotor perlit dan karbida yang bersifat keras. Kekerasan meningkat sebesar $30 \mathrm{HB}$ (19\%). Kekerasan pada rentang 157 187 HB berada pada matriks as-cast ferritic dan ferritic/pearlitic.

Foto struktur mikro menunjukkan bentuk grafit yang terbentuk, matriks yang terbentuk dan persebaran grafit nodul. Fertit merupakan area berwarna coklat sebagai matriks. Grafit merupakan nodul berwarna hitam. Perlit adalah area berwarna hitam namun tidka berbentuk nodul. Foto struktur mikro dapat dilihat pada Gambar 3 dan Gambar 4.

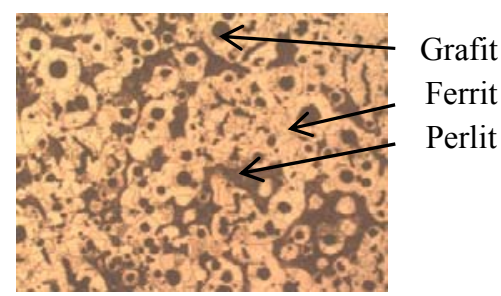

(a)

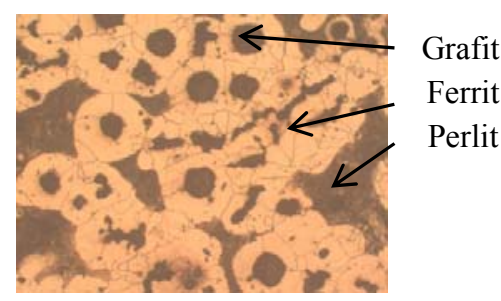

(b)

Gambar 2. Foto struktur mikro hasil pengecoran pertama, etsa nital 5\%: (a) perbesaran 50X. (b) perbesaran $400 \mathrm{X}$ 


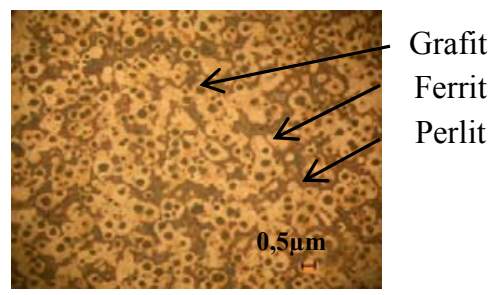

(a)

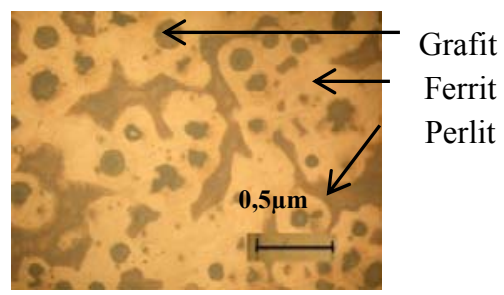

(b)

Gambar 3. Foto struktur mikro pengecoran kedua; dengan nital 5\%: (a) perbesaran 50X. (b) perbesaran $400 \mathrm{X}$

Pengamatan struktur mikro menunjukkan terbentuknya matriks feritik dengan kisaran luas area perlit 10 20\%. Pada cor pertama, luas area perlit sekitar $16 \%$ dan pada cor kedua sekitar $14 \%$. Luas area perlit tidak meningkat secara signifikas dengan sedikit penambahan $\mathrm{Cr}$.

Nodularity (tingkat kebulatan dan penyebaran grafit nodul) sedikit berbeda antara komposisi cor pertama dan kedua. Pada $0,033 \% \mathrm{Cr}$ $0,061 \% \mathrm{Mg}$ (Gambar 5) menunjukkan $80 \%$ nodularity. Pada $0,074 \%-0,08 \% \mathrm{Mg}$ (Gambar 6) menunjukkan $90 \%$ nodularity. Luas area grafit nodul relatif sama. Peningkatan unsur $\mathrm{Cr}$ dalam jumlah sedikit tidak menghambat fungsi $\mathrm{Mg}$ sebagai penyeragam distribusi nodul.

\section{KESIMPULAN}

Dari penelitian ini dapat diambil kesimpulan sebagai berikut:

1. Penambahan sedikit unsur $\mathrm{Cr}$ dapat meningkatkan nilai kekuatan tarik namun menurunkan elongasi.

2. Penambahan sedikit unsur $\mathrm{Cr}$ dapat meningkatkan nilai kekerasan.

3. Kandungan $\mathrm{P}, \mathrm{S}$ dan residu $\mathrm{Mg}$ mempengaruhi efek dari penambahan unsur Cr.

4. Peningkatan sedikit unsur $\mathrm{Cr}$ tidak memberikan efek yang signifikan dalam meningkatkan jumlah perlit dan nodularity.

\section{UCAPAN TERIMA KASIH}

Penulis menyampaikan terima kasih kepada Balai Besar Logam dan Mesin Kementerian Perindustrian yang telah mendanai dan mendukung pelaksanaan penelitian ini.

\section{DAFTAR PUSTAKA}

Bockus, S, and A Dobrovolskis. 2005. "Effect of Melting Techniques on Ductile Iron Castings Properties." Metalurgija 45: 1316.

Bockus, S, and G Zaldarys. 2011. "Evaluation of Producing Technique Factors Affecting the Matrix Microstructrure of As-Cast Ductile Iron Castings." Metallurgija 50 (1). Kaunas, Lithuania: Hrvatsko Metalursko Drustvo/Croatian Metallurgical Society: 9-12. http://hrcak.srce.hr/index.php?show=clana k\&id_clanak_jezik=91387.

Cho, G S, K H Choe, K W Lee, and A Ikenaga. 2007. "Effects of Alloying Elements on the Microstructures and Mechanical Properties of Heavy Section Ductile Cast Iron.” J. Mater. Sci. Technol 23 (1): $97-$ 101.

Gonzaga, R a, P Martínez Landa, a Perez, and P Villanueva. 2009. "Mechanical Properties Dependency of the Pearlite Content of Ductile Irons." Manufacturing Engineering 33 (2): 150-58.

Gumienny, G. 2010. "Chromium and Copper Influence on the Nodular Cast Iron with Carbides Microstructure." Archives of Foundry Engineering 10 (4): 47-54.

Jiang, Ke, Ying-dong Qu, Jun-hua You, Rongde Li, Qing-chun Xiang, and Yu-xiong Zhou. 2016. "Influence of Cr Element on Impact Fracture Process of Ductile NiResistant Alloyed Iron at Low Temperature." China Foundry Research \& Development 13 (1): 42-46. doi:10.1007/s41230-016-5082-2.

Madtha, Lisa Shifani, and Narendra Babu. 2013. "Experimental Behavioural Study Of Ductile Cast Iron Microstructure And Its Mechanical Properties." International Journal of Engineering Research 3 (3): 1470-75. www.ijera.com.

Melnikov, A P, and Y V Filipenka. 2011. "A Study the Relationship between Composition, Structure and Properties of Ductile Iron in Continuous Casting." Lit'ë I Metallurgiâ 3 (62): 11-16. 
Omran, A.M, G.T Abdel-Jaber, and M.M Ali. 2014. "Effect of $\mathrm{Cu}$ and $\mathrm{Mn}$ on the Mechanical Properties and Microstructure of Ductile Cast Iron." Journal of Engineering Research and Applications 4 (6): 90-96.

Pluphrach, Ganwarich. 2010. "Study of the Effect of Solidification on Graphite Flakes Microstructure and Mechanical Properties of an ASTM A-48 Gray Cast Iron Using Steel Molds." Songklanakarin Journal of Science and Technology 32 (6): 613-18.

Soitiski, M.S, and A Derda. 2008. "The
Influence of Selected Elements on Mechanical Properties of Ferritic Ductile Iron." Archives of Foundry Engineering 8 (1): 303-8.

Válek, T., P. Šimon, and L. Stř́lková. 2012.

"The Comparison of Selected Methods of Cast Iron Spheroidization in Industrial Conditions." Archives of Foundry Engineering 12 (2): 89-92. doi:10.2478/v10266-012-0043-8. 